\title{
Sex, drugs and self-control: why chemsex is fast becoming a public health concern
}

\section{Alastair Macfarlane}

Medical Student, King's College London, London, UK

\section{Correspondence to}

Mr Alastair Macfarlane, King's College London, 71 Etchingham Park Road, Finchley, London N3 2ED, UK; alastair.macfarlane@kcl.ac.uk

Received 12 July 2016 Revised 18 August 2016 Accepted 22 August 2016
CrossMark

To cite: Macfarlane A. J Fam Plann Reprod Health Care 2016;42:291-294.

\section{INTRODUCTION}

The sexual landscape of the UK is ever changing. Taboos and norms are in constant fluctuation, and what was perceived as odd 10 years ago is now commonplace. One growing practice in recent years, especially in the community of men who have sex with men (MSM), has been chemsex: intercourse under the influence of psychoactive substances, in particular gammahydroxybutyrate (GHB)/ gammabutyrolactone (GBL), mephedrone and crystal methamphetamine or 'crystal meth' (Table 1). These drugs heighten sexual arousal and facilitate longer sex sessions, paving the way for chemsex parties: events based in clubs, saunas or private accommodation whereby weekend-long drugs binges fuel a quick turnover of sexual partners.

Recently, various authors have called for chemsex to become a public health priority. ${ }^{1}$ There are various reasons for this, including the possible link with HIV and other sexually transmitted infection (STI) transmission, the physical and mental health effects of the drugs used in chemsex sessions, and the unwillingness of many MSM to seek help because of the perceived stigma and shame associated with their lifestyle.

This essay will discuss the most recent literature on chemsex in the UK, including epidemiology, health effects and why it should become a public health priority. I will argue that there are various approaches that the medical community and other parties can take to tackle the issue, and offer my opinion as to which might be the most effective.

\section{EPIDEMIOLOGY}

The European MSM Internet Survey (EMIS) was an online study carried out in 2010 across 38 countries in Europe, on over 180000 men, to determine knowledge, attitudes, needs and behaviour regarding STI transmission among MSM. ${ }^{2}$ A large amount of research into chemsex in particular, however, has been focused on the UK. Areas in London such as Lambeth, Southwark and Lewisham (LSL) have been studied in depth, as these harbour some of the highest numbers of MSM in the UK. ${ }^{3}$

Information about drug use and HIV/ STI prevalence in the UK became apparent from the EMIS study. Alcohol was the most commonly used drug, but recently there has been a decline in lysergic acid diethylamide (LSD) and speed, and an increase in GHB/GBL, mephedrone and crystal meth, with polydrug use being very common. This corroborates with data from Antidote, a UK lesbian/ gay/bisexual/transgender (LGBT) drug and alcohol support service. In 2005, only 3\% of presentations to Antidote were due to GHB/GBL, mephedrone and crystal meth, but in 2012 these substances accounted for $85 \%$ of presentations. ${ }^{4}$

In LSL, rates of drug use were significantly higher, as shown in Table 2. Men surveyed from these areas were $3.5 \times$ more likely to use mephedrone, $6.5 \times$ more likely to use GHB/GBL, and $7 \times$ more likely to use crystal meth in the last month compared to MSM elsewhere in England.

In the same regions, there appears to be a correlation with drug use and HIV prevalence, as shown in Table 3.

Although the EMIS study seemed to overestimate the HIV prevalence compared to national measurements ${ }^{5}$ these figures still show that in areas of higher drug use, prevalence of HIV is greater (as well as other STIs such as hepatitis C). It is difficult to draw a causal link between these two variables, but various mechanisms may be at play. 
Table 1 Summary of the 'party drugs' commonly used at chemsex parties

\begin{tabular}{|c|c|c|c|}
\hline Drug & $\begin{array}{l}\text { Gammahydroxybutyrate (GHB) and } \\
\text { gammabutyrolactone (GBL) }\end{array}$ & Mephedrone & $\begin{array}{l}\text { Crystal methamphetamine } \\
\text { ('crystal meth') }\end{array}$ \\
\hline Description & $\begin{array}{l}\text { Closely related drugs with sedative and anaesthetic } \\
\text { effects; GBL is metabolised to GHB after entering } \\
\text { the body }\end{array}$ & $\begin{array}{l}\text { Closely related to amphetamines like speed/ } \\
\text { ecstasy, mephedrone is often sold over the } \\
\text { Internet as plant food or bath salt and } \\
\text { labelled 'unfit for human consumption' so } \\
\text { that dealers can avoid arrest }\end{array}$ & $\begin{array}{l}\text { A purer version of the group of } \\
\text { stimulants called } \\
\text { methamphetamines }\end{array}$ \\
\hline Class & $\mathrm{C}$ & B & A \\
\hline Appearance & Odourless, colourless, oily liquid & Fine white/yellowish powder & Tablets/powder/crystals \\
\hline Street names & $\begin{array}{l}\text { G, Gina, Grievous Bodily Harm, Liquid X, Bedtime } \\
\text { Scoop }\end{array}$ & Meow Meow, Meph, White Magic, M-cat & Tina, Meth, Ice, Glass \\
\hline Administration & Swallowed as a liquid or added to drinks & $\begin{array}{l}\text { Snorted, wrapped in paper and swallowed } \\
\text { (bombed), taken as capsules or pills, injected, } \\
\text { administered rectally ('booty bumping') }\end{array}$ & $\begin{array}{l}\text { Smoked, snorted, administered } \\
\text { rectally, mixed with water and } \\
\text { injected }\end{array}$ \\
\hline Effects & $\begin{array}{l}\text { Euphoria, disinhibition, drowsiness, sexual } \\
\text { stimulation, relaxant effects can make receptive } \\
\text { anal intercourse easier or more pleasurable }\end{array}$ & $\begin{array}{l}\text { Alertness, confidence, euphoria, sexual } \\
\text { stimulation, disinhibition }\end{array}$ & $\begin{array}{l}\text { Euphoria, increased energy during } \\
\text { sex, confidence, impulsivity, } \\
\text { disinhibition }\end{array}$ \\
\hline $\begin{array}{l}\text { Negative } \\
\text { effects }\end{array}$ & $\begin{array}{l}\text { Particularly dangerous with alcohol, can cause } \\
\text { unconsciousness ('G sleep'), memory loss, coma } \\
\text { and death; very easy to overdose }\end{array}$ & Nausea, paranoia, anxiety, hallucinations & $\begin{array}{l}\text { Sleep disruption, palpitations, } \\
\text { severe come down }\end{array}$ \\
\hline
\end{tabular}

Table 2 Party drug' use among men who have sex with men (MSM) in Lambeth/Southwark/Lewisham (LSL), London and England, taken from the European MSM Internet Survey (EMIS)

\section{Percentage of MSM who used drugs in the last} 4 weeks

\begin{tabular}{lrll}
\cline { 2 - 4 } Drug & LSL & Elsewhere in London & Elsewhere in England \\
\hline Crystal meth & 4.9 & 2.9 & 0.7 \\
Mephedrone & 10.2 & 5.2 & 2.9 \\
GHB/GBL & 10.5 & 5.5 & 1.6 \\
\hline
\end{tabular}

LSL reports significantly higher drug use than elsewhere. ${ }^{2}$

$\mathrm{GBL}$, gammabutyrolactone; GHB, gammahydroxybutyrate.

Table 3 HIV prevalence among men who have sex with men (MSM) in Lambeth/Southwark/Lewisham (LSL), London and England, taken from the European MSM Internet Survey (EMIS)

\begin{tabular}{llll}
\hline Area & LSL & $\begin{array}{l}\text { Elsewhere } \\
\text { in London }\end{array}$ & $\begin{array}{l}\text { Elsewhere } \\
\text { in England }\end{array}$ \\
\hline HIV prevalence (\%) & 19.7 & 13.7 & 8.4 \\
\hline As baselin
\end{tabular}

As a baseline, the prevalence of HIV in the UK in all men is $0.4 \%{ }^{2}$

\section{CHEMSEX AND HIV PREVALENCE}

One mechanism by which drug use could facilitate HIV transmission is through sexual disinhibition and risktaking behaviour. As Table 1 illustrates, all three types of drug currently popular at chemsex parties cause disinhibition, with side effects such as impulsivity and increased sexual arousal. This concoction of psychological changes predisposes to risky sexual behaviour such as unprotected anal intercourse (UAI). Indeed, in a qualitative study on the behaviour of 30 men from LSL, one-third of the interviewees admitted to having had unintentional UAI with sero-discordant or sero-unknown partners as a result of drug intoxication. ${ }^{3}$
Whilst serosorting (choosing sexual acts based on beliefs about one's own and one's partner's HIV status) appears common in chemsex parties and would theoretically lower the risk of transmission, some HIV-positive individuals have admitted initiating unprotected intercourse whilst not explicitly asking about their partner's HIV status, and making judgments based on appearance (e.g. if they were tattooed) or sexual preferences (e.g. if they were open to sexual intercourse without condoms then they were already HIV-positive). ${ }^{6}$ Needless to say these inferences would likely facilitate HIV transmission.

Another reason drug use is associated with HIV transmission could be more direct. A common effect of party drugs in chemsex is the ability to have intercourse for extended periods of time, sometimes up to 72 hours. $^{3}$ HIV transmission may therefore be facilitated by a higher incidence of rectal trauma and penile abrasions, especially given the anaesthetic properties of some substances. Longer sex sessions also permit individuals to have sex with multiple partners, averaging five per session. ${ }^{1}$

Chemsex is occasionally associated with injection of substances, particularly crystal meth. This practice, known informally as 'slamming', is confined to a minority of the chemsex community, but the sharing of needles has been described as a "perfect storm" for HIV and hepatitis $\mathrm{C}$ transmission.

Finally, many party drugs trigger sleep disruption and memory disturbances, which, when coupled with extended sex sessions, make it very easy to forget post-exposure prophylaxis (PEP) for HIV. PEP should ideally be taken within 24 hours of having risky sexual intercourse, and is unlikely to work after 72 hours. 
OTHER SEXUAL PROBLEMS ASSOCIATED WITH

\section{CHEMSEX}

Besides STI transmission, other sexual health problems related to chemsex appear to be rising. Antidote reported that referrals from sexual health services accounted for $8 \%$ of total referrals in 2005 , but increased to $63 \%$ in $2012 .{ }^{4}$ This jump could represent an increased awareness of Antidote, but may also reflect problems associated with a changing drug landscape in the chemsex community.

Many of these problems appear to stem directly from the effects of party drugs themselves: impotence, sexual unhappiness and lack of intimacy. Whilst substances like GHB/GBL, mephedrone and crystal meth increase sexual arousal, they paradoxically make it harder to get or maintain an erection. Use therefore commonly includes substances like Viagra ${ }^{\circledR}$ to counteract these effects, but subsequent dependence impairs erectile function when sober. Furthermore, many individuals lamented the fact that they found it difficult to sustain intimate relationships whilst chemsex parties were a part of their life. ${ }^{3}$

\section{PHYSICAL AND MENTAL HEALTH PROBLEMS ASSOCIATED WITH CHEMSEX}

Chemsex carries with it the risk of other medical problems, both physical and psychological. Acutely, a major issue is drug overdose, which is much higher in the chemsex community than the general population. Overdose is particularly common with GHB/GBL as it is short acting and requires regular re-dosing, which is problematic as it causes temporal disorientation.

The effects of overdose can be diverse, from unconsciousness (going into a ' $G$ hole'), agitation, aggression, amnesia or unintentional injury to individuals themselves or to others. Many of these effects require hospitalization, and unfortunately loss of consciousness and amnesia mean that sexual assault is an all-too-common problem in the chemsex community. ${ }^{3}$

Although many party drugs may not be acutely problematic if well-dosed and taken individually, in reality they are taken in combination - both with other recreational substances and therapeutic ones such as antiretroviral medication - and this can lead to serious drug interactions. ${ }^{8}$

Many individuals have described problems with mental health as well, from acute irritability and depression following a drugs binge, to long-term psychological sequelae such as memory loss, psychosis and dependency. Many of the longer-term phenomena were caused by perceived lost time, harms related to employment and finance, and social isolation when away from chemsex parties. ${ }^{3}$

\section{GEOSOCIAL NETWORKING APPLICATIONS}

Is chemsex the sole cause for these problems seen in the MSM community? HIV prevalence in the UK is still rising among MSM, which is partly due to increased testing but also ongoing transmission. Although chemsex may play a part, another factor could be geosocial networking applications (apps), whereby individuals create a public profile online and interact with others via their mobile phone. Several of these apps are designed exclusively for MSM, and are commonly used for sex and relationships.

These apps are often used as a medium to obtain drugs from nearby sources, ${ }^{3}$ which could explain some of the medical and sexual problems described. However, a study in the USA has shown that meeting partners through these apps increases the rate of STI transmission compared to meeting through in-person venues (e.g. bars) or through MSM-specific hook-up websites, independent of drug exchange. ${ }^{9}$

Despite the correlation between apps and some public health issues afflicting MSM, chemsex still appears to underlie the majority of recent changes seen in this demographic, particularly in the UK. Indeed, many chemsex parties are organised via apps and so the connection could be complex. For example, some authors are worried that apps may be normalising drug use and promiscuity, aggravating the stigma that already surrounds the MSM community. ${ }^{3}$ Many individuals attend chemsex events to escape stigma, so a self-perpetuating cycle occurs.

\section{WHY SHOULD CHEMSEX BECOME A PUBLIC HEALTH PRIORITY?}

Although more information is needed about the impact of chemsex on public health in the UK, various issues are already starting to emerge. The practice is undeniably associated with physical, mental and sexual health problems, and may be facilitating the spread of STIs in the MSM community.

Increasing numbers of men are becoming involved in chemsex, especially in areas with high MSM populations. ${ }^{6}$ Given the addictive nature of the practice, and the health consequences associated with it, I feel that it should become a public health priority.

In the UK, clinicians are provided with minimal advice from the National Institute for Health and Care Excellence on psychoactive drugs, and nothing specifically related to chemsex. ${ }^{1}$ Furthermore, generic drug services in the UK are aimed at opiate use, and are poorly equipped to handle drugs like GHB/GBL, mephedrone and crystal meth. ${ }^{10}$ Given the significant cuts to sexual health funding, a novel approach should be taken to tackle this growing issue.

\section{WHAT ARE THE SOLUTIONS TO CHEMSEX- ASSOCIATED PROBLEMS IN THE UK?}

One problem voiced by individuals who are negatively affected by chemsex is the perceived lack of support for their medical problems. ${ }^{3}$ General practitioners (GPs) are often seen as too judgmental, which could be down to a poor understanding by GPs of what chemsex entails. One author has recently 
recommended that GPs become more familiar with the notion of chemsex to aid history taking and onward referral for patients. ${ }^{8}$

Although sexual health clinics are regarded by some chemsex users as effective, ${ }^{3}$ many appear to lack the facilities and expertise to manage drug problems. Similarly, while many individuals seek help for their chemsex-associated drug habits, they have expressed concern for the relative lack of knowledge and support from specialist drug centres on sexual health problems.

One solution could be to provide training to sexual health services and specialist drug centres on all the aspects of chemsex and the biopsychosocial problems therein. If funding restricts this, specialist referrals should be made more readily available and a multidisciplinary approach to some chemsex patients considered.

Information about chemsex should also be made more accessible. This would include not only advice about how to contact specialist services, but also assistance on harm reduction, such as safe sexual and drug practices, STI transmission and social stigma.

\section{CONCLUSIONS}

Chemsex is a growing problem in the UK. A significant proportion of MSM are regularly administering a concoction of substances to facilitate sexual arousal and longer sex sessions with multiple partners. This practice is fraught with public health issues ranging from drug overdose to HIV transmission, and is fast becoming a burden on sexual health services across the UK. To help solve these problems, information about harm reduction should be made readily available, and specialist services should be set up that are adequately equipped to manage patients with a range of physical, psychological and sexual health concerns.
Competing interests None declared.

Provenance and peer review Not commissioned; externally peer reviewed.

\section{REFERENCES}

1 McCall H, Adams N, Mason D, et al. What is chemsex and why does it matter? BMJ 2015;351:2.

2 Weatherburn P, Schmidt AJ, Hickson F, et al. The European Men-who-have-sex-with-men Internet Survey (EMIS): design and methods. Sex Res Soc Policy 2013;10: 243-257.

3 Bourne A, Reid D, Hickson F, et al. The Chemsex Study: Drug Use in Sexual Settings Among Gay and Bisexual men in Lambeth, Southwark and Lewisham. London, UK: Sigma Research, London School of Hygiene and Tropical Medicine, 2014. http://www.sigmaresearch.org.uk/chemsex

4 Stuart D. Sexualised drug use by MSM: background, current status and response. HIV Nurs 2013;13:6-10.

5 Marcus U, Hickson F, Weatherburn P, et al. EMIS Network. Prevalence of HIV among MSM in Europe: comparison of self-reported diagnoses from a large scale internet survey and existing national estimates. BMC Public Health 2012;12:978.

6 Bourne A, Reid D, Hickson F, et al. Illicit drug use in sexual settings ('chemsex') and HIV/STI transmission risk behaviour among gay men in South London: findings from a qualitative study. Sex Transm Infect 2015;91:564-568.

7 Kirby T, Thornber-Dunwell M. High-risk drug practices tighten grip on London gay scene. Lancet 2013;381:101-102.

8 Ma R, Perera S. Safer 'chemsex': GPs' role in harm reduction for emerging forms of recreational drug use. Br J Gen Pract 2016;66:4-5.

9 Beymer MR, Weiss RE, Bolan RK, et al. Sex on demand: geosocial networking phone apps and risk of sexually transmitted infections among a cross-sectional sample of men who have sex with men in Los Angeles county. Sex Transm Infect 2014;90:567-572.

10 Bourne A, Reid D, Hickson F, et al. "Chemsex" and harm reduction need among gay men in South London. Int J Drug Policy 2015;26:1171-1176.

\section{Informative or amusing fillers invited}

Sometimes, in the process of finalising each journal issue for print publication, we are left with blank spaces at the end of articles - like this one. We like to make good use of these spaces when we can, and thus welcome 'fillers' of up to 250 words which inform or entertain.

These fillers can be factual, funny, challenging or creative, but they need to relate to sexual health. Have you come across something wise, informative or amusing on social media which is relevant to our readers? Have you learned something in another field that you think SRH practitioners might benefit from? Have you heard something thought-provoking in conversation, or have you a haiku up your sleeve?

We cannot guarantee publication, but welcome all ideas and submissions, and will publish these where suitable, and as space in a print journal issue allows. We will let you know if we are unable to publish your contribution for any reason.

All submissions should be submitted to the Journal Editorial Office at journal@fsrh.org. 